\title{
Static and dynamic stability of gravi-inertial sensors with capacitive differential system of sensitivity adjustment
}

\author{
Gilavdary I. ${ }^{1}$, Mekid S. ${ }^{2}$, Riznookaya N. ${ }^{1}$, Abdul Sater A. ${ }^{1}$ \\ ${ }^{1}$ Belarusian National Technical University, \\ Nezavisimosty Ave., 65, 220013, Minsk, Belarus \\ ${ }^{2}$ King Fahd University of Petroleum \& Minerals, Mechanical Engineering Department, \\ Dhahran, 31261, Saudi Arabia
}

Поступила 28.12.15

Принята к печати 28.03.2016

The design of a gravi-inertial sensor with an elastically suspended sensing mass exhibiting a maximum sensitivity and minimum noise level is being studied. It is conceived that such a sensor contains a torsion mass-spring system, a capacitive pick-off circuit to detect motions of the sensing mass, and a capacitive system to reduce torsion stiffness. Both capacitive systems are combined into a single differential capacitance electrostatic system. The torsion stiffness is reduced by applying an electric field. Problems resulting from the electrostatic asymmetry of the differential system are studied analytically and numerically. The quasi-static and dynamic modes of the free movement of the sensing mass, in the absence of energy loss, are considered. The angular intervals of stability of the sensing mass movement in the electrostatic field, depending on the differential system asymmetry parameter and a frequency of free oscillations «proof mass», are calculated.

Keywords: Gravi-inertial sensors, capacitive differential sensor, pull-in effect, asymmetry of a differential sensor.

DOI: $10.21122 / 2220-9506-2016-7-1-16-23$

\begin{tabular}{ll}
\hline Адрес для переписки: & Address for correspondence: \\
Джсилавдари И. & Gilavdary I. \\
Белорусский национальный технический университет, & Belarusian National Technical University, \\
nр. Независимости, 65, 220013, г. Минск, Беларусь & Nezavisimosty Ave., 65, 220013, Minsk, Belarus \\
e-mail:gilavdary@bntu.by & e-mail:gilavdary@bntu.by \\
\hline Для цитирования: & For citation: \\
Gilavdary I., Mekid S., Riznookaya N., Abdul Sater A. & Gilavdary I., Mekid S., Riznookaya N., Abdul Sater A. \\
Static and dynamic stability of gravi-inertial sensors with capacitive & Static and dynamic stability of gravi-inertial sensors with capacitive \\
differential system of sensitivity adjustment. & differential system of sensitivity adjustment. \\
Приборы и методы измерений. & Priboryi metody izmerenj [Devices and Methods of Measurements], \\
2016. - Т. 7, № 1.- С. 16-23. & 2016, vol. 7, no. 1, pp. 16-23. \\
DOI: $10.21122 / 2220-9506-2016-7-1-16-23$ & DOI: 10.21122/2220-9506-2016-7-1-16-23
\end{tabular}




\section{Introduction}

Designing a supersensitive gravi-inertial sensors measuring linear and angular accelerations of moving objects with second derivatives of gravitational potential, on the Earth surface and in circumplanetary space is a problem that stands in front of science and developers since the late $50^{\text {th }}$ century until currently [1-6].

Typically such sensors comprise a sensing mass (often called as a movable mass, or proof mass (PM)) retained relative to the housing by an elastic mechanical coupling. This elastic coupling is characterized by a natural frequency of free oscillations of PM along the axis of the sensor sensitivity. In order to increase the sensitivity of the sensor, it is required to reduce this frequency, the internal noise and the noise of a read-out system [7].

Actually the capacitive microelectromechanical (MEM) - accelerometers are broadly known where electrical capacitors are used for reading of the desired signal, and MEM capacitive actuators, where electrical capacitors and electrical fields are used to control the movement of the elastically suspended $\mathrm{PM}$ and to drive its resonant frequency.

Actuators usually establish the limits of motion control while the change of the resonant frequencies are limited by the pull-in effect [8]. This effect is due to the fact that, if PM deflects from their equilibrium position, the electrostatic forces will grow faster than the elastic force holding the PM near the equilibrium position. When the electric forces start to exceed the mechanical strength, the system becomes unstable and the PM tends to stick the structural elements of the device carrying electrical charges.

Typically the electric field forces in measuring devices with capacitive readout are too small to achieve the pull-in effect. But there is possibility to adjust the stiffness in a narrow interval [9]. In [10] the gravi-inertial sensor was proposed in which the function of the capacitive sensor and actuator are combined into a single differential capacitive system. In this sensor, it was assumed that the electric field forces are enough to compensate elastic forces in the direction of the sensitive axis. It was assumed that such a combination in the graviinertial sensors will allow achieving maximum sensitivity and minimum level of noise.

Capacitive sensors are non-linear due to the physical properties of electrical capacitors. Therefore, differential electrostatic systems are often used in measuring instruments, because nonlinearity may be partly compensated there [11]. However, the effect of asymmetry of the differential capacitive systems is still not fully explored. Such study was carried out for a quasi-static displacement of PM in the gravi-inertial sensors [12], where it was shown that it is the asymmetry of the differential electrostatic system that sets a limit to reduce the torsion stiffness of the suspension of PM using the electrostatic field.

The purpose of this work is within the framework of a unified approach to investigate the effect of asymmetry of the nonlinear differential electrostatic system on PM movement in quasi-static mode and in the free oscillation mode as accurately as possible within the selected mathematical model. Research is carried out for a lumped system with one degree of freedom. In this step of research energy losses are not considered.

\section{Investigation of the stability of quasi-static mode of the PM in an electric field}

A simplified scheme of a gravi- inertial sensor chosen for the calculations is shown in Figure 1. The description details of this scheme and original calculations of the capacitor with the inclined plate are given in [12].

The elastic $M_{m}$ torque and the electrical torque $M_{e}$ affect the PM in this sensor. Dependence of the total torque acting on the PM angle $\varphi$ deviations from the equilibrium position can be written as [12]:

$M(v)=M_{m}(v)-M_{e}(v)=B\left[k_{1} v-\frac{8 v+\gamma(1+v)^{2}}{\left(1-v^{2}\right)^{2}}\right]$,

where: $v=\frac{\varphi}{\varphi_{m}}$; parameter $\varphi_{m}=\frac{h_{0}}{L} \ln \left(\frac{a_{1}}{a_{2}}\right)$ related

to the geometry of the system; $h_{0}$ - the gap between the capacitor's plates when $\varphi=0$;

$a_{1}=\frac{1}{h_{0}} \ln \left(r+\frac{L}{2}\right), a_{2}=\frac{1}{h_{0}} \ln \left(r-\frac{L}{2}\right) ;$

$k$ - the mechanical torsion stiffness;

$k_{1}=\frac{k \varphi_{m}}{B} ; B=\frac{1}{2} \frac{C_{0} U^{2}}{\varphi_{m}}$.

When Eq. (1) was used, it was assumed that the total capacity of a first pair of capacitors $C_{1}+C_{3}=2 C_{0}$; and the total capacitance of the second pair of capacitors $C_{2}+C_{4}=\left(1+\gamma_{1}\right) C_{1}+\left(1+\gamma_{2}\right) C_{3}=(2+\gamma) C_{0}$, where $\gamma=\gamma_{1}+\gamma_{2}$ - parameter characterizing the asymmetry of an electrostatic system. 


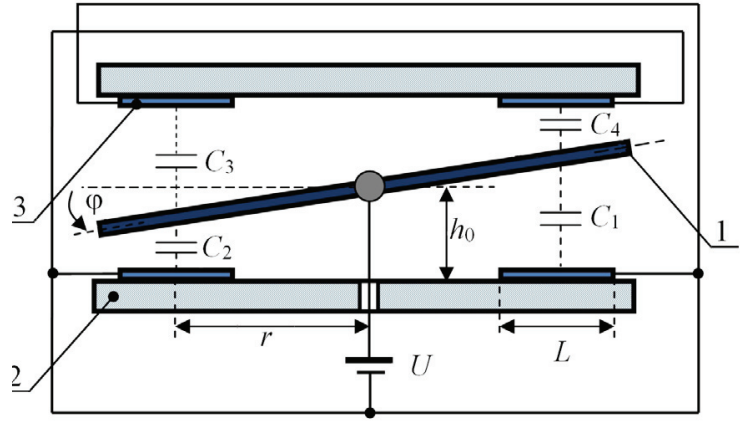

Figure 1 - Model of the differential sensor: 1 - conductive PM; 2 - non-conductive plate; 3 - electrode. The resilient torsion is shown in the PM center

It follows from Eq. (1) that with the absence of an electric field $(U=0)$ the PM is located in a equilibrium position (angle $v=0$ ). If the electric field is turning on sluggishly, such that the kinetic energy of PM's motion can be neglected, the PM will turn to a new equilibrium position with the angle $v_{s t}$. By solving the equation $M(v)=0$, we can find the relation between the angle of $v$ and parameter $\gamma$ under quasistatic motion of PM:

$\gamma(v)=v \frac{\left(v^{2}-1\right)^{2} k_{1}-8}{(v+1)^{2}}$.

The dependence of $\gamma(v)$ is shown graphically in Figure 2. The calculations shown below will use the parameters of the sensor listed in Table.

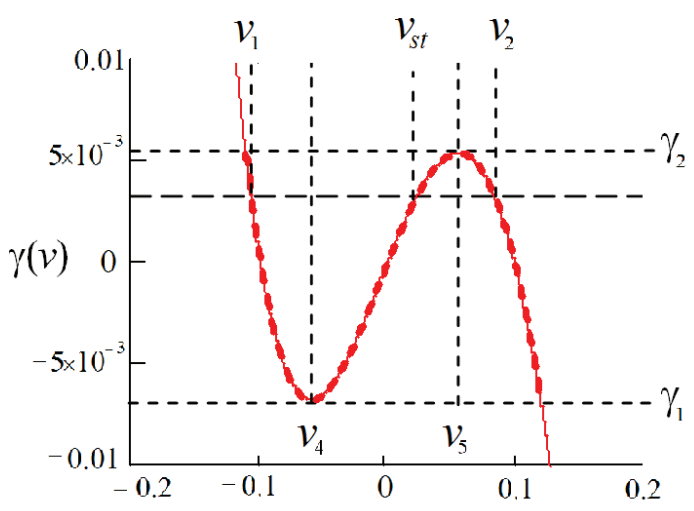

Figure 2 - Dependence $\gamma(v)$ is obtained from the equation $M(v)=0$ and the characteristic angles from $v_{1}$ to $v_{5}$. The angle $v_{s t}$ is the static equilibrium of PM

In this table, the parameter $f$ - natural frequency of the PM when the electric field is switch off ( $U=0), f_{0}$ - the natural frequency of the PM if the electric field is turned on.
Table

Parameters of the design model of the sensor

\begin{tabular}{cc}
\hline$I_{z}, \mathrm{~kg} \cdot \mathrm{m}^{2}$ & $4,914 \cdot 10^{-4}$ \\
\hline$k, \mathrm{~N} \cdot \mathrm{m} / \mathrm{rad}$ & 4 \\
\hline$f, \mathrm{~Hz}$ & 14,36 \\
\hline$f_{0}, \mathrm{~Hz}$ & 2 \\
\hline$L, \mathrm{~m}$ & 0,035 \\
\hline$r, \mathrm{~m}$ & 0,0525 \\
\hline$h_{0}, \mathrm{~mm}$ & 0,1 \\
\hline$\varphi_{m^{\prime}} \mathrm{rad}$ & $1,98 \cdot 10^{-3}$ \\
\hline$C_{0}, \mathrm{pF}$ & 123,9 \\
\hline
\end{tabular}

In the Figure 2, each value of $\gamma$ in an interval $\gamma_{1}<\gamma<\gamma_{2}$ corresponds to three values of the angle $v$, in which $M=0$ (analytical values $\gamma_{1}$ and $\gamma_{2}$ are defined below). It is proved beneath that in the angular range between the values $v_{1}$ and $v_{2}$ are corresponding to a specific value $\gamma$ (in Figure 2, angles $v_{1}$ and $v_{2}$ are matching the value of the parameter $\gamma=0,003$ ), the effect of pull-in does not occur, that means the PM deviation from the angle $v_{s t}$ is stable. Solving the Eq. $M(\mathrm{v})=0$ leads to Eq. $g 5(v)=0$ with the polynomial of the fifth degree

$g 5(v)=\left(-k_{1}\right) v^{5}+2 k_{1} v^{3}+\gamma v^{2}+\left(\gamma+8-k_{1}\right) v+\gamma$.

In general, this equation can not be solved analytically. However, if first term is neglected, one obtains an equation of the third degree $g 3(v)=0$, where,

$g 3(v)=2 k_{1} v^{3}+\gamma v^{2}+\left(2 \gamma+8-k_{1}\right) v+\gamma$.

The relations of $g 5(v)$ and $g 3(v)$ are compared to each other in the Figure 3. It is obvious that for the sensor with the values taken from the Table in the angular range between $v_{1}$ and $v_{2}$, the curves practically are coincided.

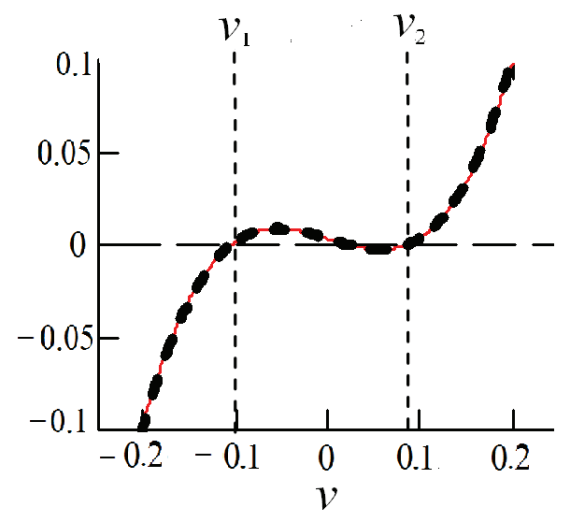

Figure 3 - The relations of $\mathrm{g} 5(v)$ (continuous line) and g3(v) (dashed line) 
Eq.(4) has an analytical solution. This solution can be found using the trigonometric Vieta formulas [13]. So that, if the polynomial of third order has the form $a v^{3}+b v^{2}+c v+d=0$, the parameters $Q, R, S$ and $\psi$ have to be determined using the formulas:

$Q=\frac{1}{9}\left[\left(\frac{b}{a}\right)^{2}-3 \frac{c}{a}\right]$,

$R=\frac{1}{54}\left[2\left(\frac{b}{a}\right)^{3}-9 \frac{b c}{a^{2}}+27 \frac{d}{a}\right]$,

$S=Q^{3}-R^{2}$,

$\psi=\frac{1}{3} \arccos \left(\frac{R}{Q^{3 / 2}}\right)$.

If $S>0$, the equation $g 3(v)=0$ has three real roots, and the position of the equilibrium $v_{s t}$ and quasi-static PM deviations between the points $v_{1}$ and $v_{2}$ are stable. Graph of $\operatorname{sign} S(\gamma)$ in the sensor is shown in Figure 4.

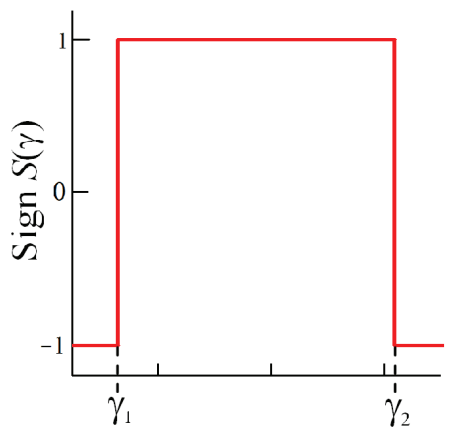

Figure 4 - The relation of the parameter sign $S(\gamma)$

It can be seen that in the range $\gamma_{1}<\gamma<\gamma_{2}$ the parameter $\mathrm{S}>0$ indeed. In this case, the roots of the equation (4) follow to (6):

$v_{1}=2 \sqrt{Q} \cos \psi-\frac{1}{3} \frac{b}{a}$,

$v_{2}=-2 \sqrt{Q} \cos \left(\psi+\frac{2 \pi}{3}\right)-\frac{1}{3} \frac{b}{a}$,

$v_{3} \equiv v_{s t}=-2 \sqrt{Q} \cos \left(\psi-\frac{2 \pi}{3}\right)-\frac{1}{3} \frac{b}{a}$.

Using the parameters from the Table, if $\gamma=0.003$, one has $v_{1}=-0,10534(-0,10561), v_{2}=0,08450(0,08$ $468), v_{s t}=0,02066(0,02066)$. Here in parentheses are shown the values of the roots obtained while solving the equation $g 5(v)=0$.

The angles $v_{4}$ and $v_{5}$, corresponding to the extreme values of the parameter $\gamma$ (shown in Figure 2), are the real roots of an algebraic equation of the fourth order:

$3 v^{4}+8 v^{3}+6 v^{2}-\left(1-\frac{8}{k_{1}}\right)=0$.

This equation can be solved analytically. If to denote $u=f_{0} / f$, and to introduce the designation as:

$$
\begin{aligned}
& z_{1}(u)=\frac{8}{27}(1+u)\left(1-u^{2}\right) ; \\
& z_{2}(u)=\sqrt{4 z_{1}(u)^{1 / 3}+9 z_{1}(u)^{2 / 3}+4\left(1-u^{2}\right)} ; \\
& z_{3}(u)=\frac{\sqrt{16 \sqrt{z_{1}(u)}+z_{2}\left(8 z_{1}(u)^{1 / 3}-9 z_{1}(u)^{2 / 3}\right)-4 z_{2}\left(1-u^{2}\right)}}{6 z_{1}(u)^{1 / 6} z_{2}(u)^{1 / 2}},
\end{aligned}
$$

the angles $v_{4}$ and $v_{5}$ are determined by the formulas:

$$
\begin{aligned}
& v_{4}(u)=\frac{z_{2}(u)}{6 z_{1}(u)^{1 / 6}}-z_{3}(u)-\frac{2}{3} ; \\
& v_{5}(u)=\frac{z_{2}(u)}{6 z_{1}(u)^{1 / 6}}+z_{3}(u)-\frac{2}{3} .
\end{aligned}
$$

Extreme values of parameter $\gamma$ can be calculated from Eq. (2), namely $\gamma_{1}=\gamma\left(v_{4}\right)$, and $\gamma_{2}=\gamma\left(v_{5}\right)$.

It should be noted that the angles $v_{4}$ and $v_{5}$ do not depend on $\gamma$, but depend only on the parameter $u$. Therefore, we can create the relation of $\gamma_{1}(u)=\gamma\left(v_{4}(u)\right)$ and $\gamma_{2}(u)=\gamma\left(v_{5}(u)\right)$ which give an idea about the actual achievable minimum values of frequency $f_{0}$, determining the sensitivity of the sensor for a given value of the parameter $\gamma$. The required relations for the sensor with the parameters for Table are shown in Figure 5.

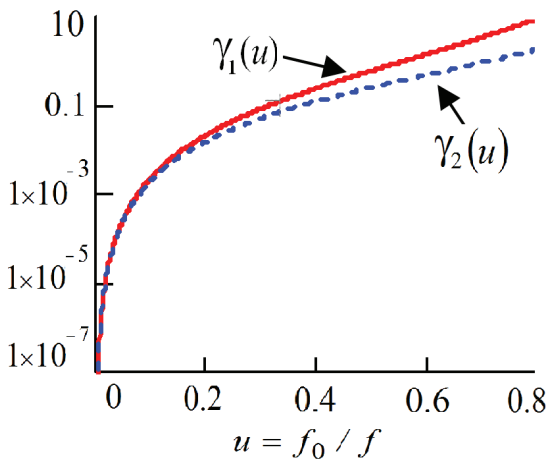

Figure 5 - Dependence of the maximum permissible values of a parameter $\gamma$ in the mode of quasi-static stability of the PM on the relative frequency $u$

\section{Investigation of the stability of free oscillations of the PM in an electric field}

Stability of free oscillations of PM is determined by the relations of the potential energy $W_{p o t}(\varphi)$ of the angle $\varphi$. Integrating $M(\varphi)$, if $W_{p o t}(0)=0$, gives: 


$$
W_{p o t}(v)=B \varphi_{m} v\left[\frac{k_{1} v\left(1-v^{2}\right)-2(\gamma+4) v-2 \gamma}{2\left(1-v^{2}\right)}\right] .
$$

The relation of $W_{p o t}(v)$ for the symmetric and asymmetric sensors is shown in Figure 6. It shows that the asymmetry of the capacitance of the system disturbs the symmetry of the potential well. Angles $v=v_{01}$ and $v=v_{02}$ - are the extreme values range of stability of the sensor in case of $\gamma=0$. Similarly, angles $v=v_{1}$ and $v=v_{2}$ have the same sense, but in case when $\gamma=0,003$.

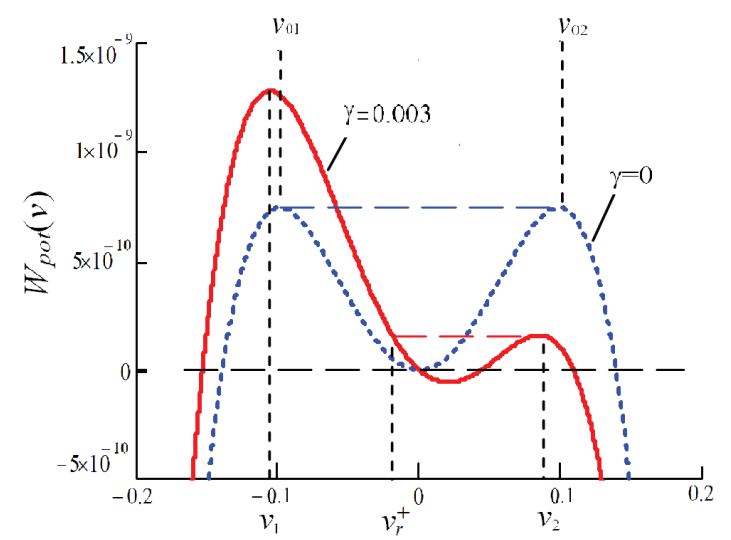

Figure 6 - The relation of the potential energy $W_{p o t}(v)$ with respect to the angle of deflection PM,when $\gamma=0$ и $\gamma=0,003$

Figure 6 indicates that, if $\gamma>0$, the free movement of PM can exist only in the interval of angles $v_{r}^{+}<v<v_{2}$. Angle $v_{r}^{+}$can be named as «a turning point». PM velocity is absent at the point $v_{2}$. The angle $v_{r}^{+}$will be defined below analytically.

It is easy to see the characteristic features dynamics of a stable movement PM in symmetric and asymmetric sensors from their phase portraits. If a velocity PM is absent in the point $v=v_{2}$, according to the law of conservation of energy, the formula of the angular velocity $\mu(v)$ of PM with respect to the angle $v$ is

$$
\mu(v)= \pm \sqrt{\frac{2}{I_{z}}\left[W_{p o t}\left(v_{2}\right)-W_{p o t}(v)\right]} .
$$

The phase trajectories are shown in Figure 7. When $\gamma=0$, these trajectories correspond to a stable system in the range $v_{01}<v<v_{02}$, and when $\gamma=0,003$, a stable system is in the range $v_{r}^{+}<v<v_{2}$.

To calculate the angle $v_{r}^{+}$, the equation $\mu(v)=0$ has to be solved. From equations (12) and (13), introducing the notations:

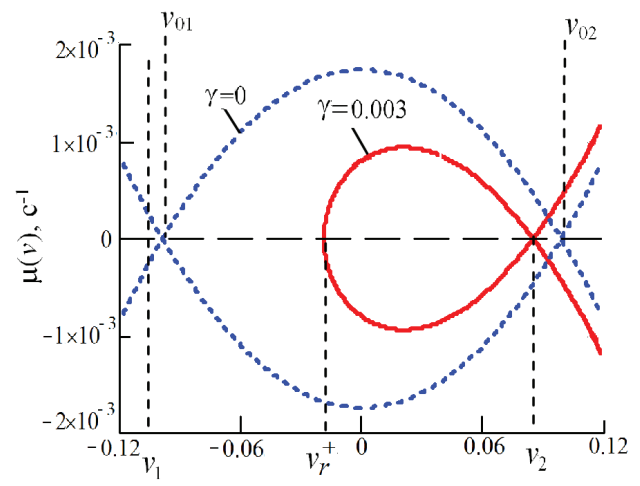

Figure 7 - The phase curves of the free movement of PM when $\gamma=0$ and $\gamma=0,003$

$k_{r}=k_{1}\left(1-v_{2}^{2}\right), a_{r}=k_{r}, b_{r}=v_{2} k_{r}$,

$c_{r}=2 \gamma\left(1+v_{2}\right)-k_{r}+8, d_{r}=2 \gamma\left(1+v_{2}\right)$,

the equation determining $v_{r}^{+}$follows to (15):

$a_{r} v_{r}^{3}+b_{r} v_{r}^{2}+c_{r} v_{r}+d_{r}=0$.

Using Vieta formulas of (5)-(6) and the value of angle $v_{2}=0,08468$, obtained above, for sensor parameters in Table and for $\gamma=0,003$, it can be found $v_{r}^{+}=-0,01878$. Then the interval of stable free oscillations of PM will be determined by the formulas:

when $\gamma>0$, this interval is given by:

$\Delta_{d}^{+}=v_{2}-v_{r}^{+}$;

when $\gamma<0$, this interval is given by:

$\Delta_{d}^{-}=v_{r}^{-}-v_{1}$,

where $v_{r}^{+}$and $v_{r}^{-}-$the coordinates of «turning points» when $\gamma>0$ and $\gamma<0$, respectively.

In general, in contrast to the stability of the quasistatic intervals of PM movement, where the formula for calculating the boundary points does not depend on the sign of $\gamma$, the calculation of intervals of dynamic stability determined in Eq.(16) and Eq.(17) should be carried out separately for $\gamma>0$ and for $\gamma<0$, because dependence of $v_{r}^{+}$and $v_{r}^{-}$on $\gamma$. The formulas for the calculation of $v_{r}^{-}$differ from similar formulas for $v_{r}^{+}$by replacing $v_{2}$ to $v_{1}$ in the formulas (14).

The calculations of $\Delta_{d}^{+}$and $\Delta_{d}^{-}$with respect to the parameter $\gamma$ are shown in Figure 8 .

Here a similar relation for the stability of the quasi-static range $\Delta v_{s t}=v_{2}-v_{1}$ is also shown. Figure 8 shows that the intervals of dynamic stability de- 
creases sharply with increasing $\gamma$ while the range of static stability changes only slightly throughout the range of acceptable values $\gamma$.

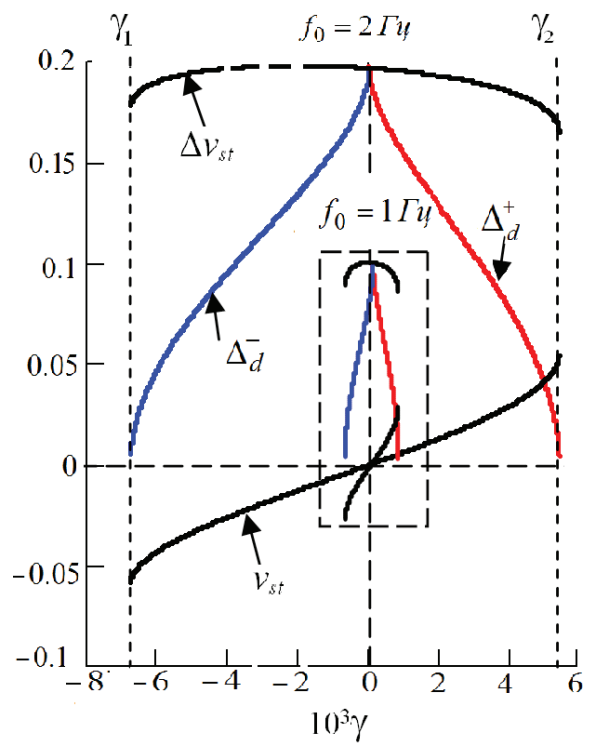

Figure 8 - The relation of static $\Delta v_{s t}$, and dynamics $\Delta_{d}^{+}$, and $\Delta_{d}^{-}$stables angular intervals, and also the angle of static equilibrium $v_{s t}$ with respect to the asymmetry parameter $\gamma$ when the value of the natural frequency $f_{0}=2 \mathrm{~Hz}$. In the rectangle highlighted in dashed lines, shows similar curves calculated with the same scale, when $f_{0}=1 \mathrm{~Hz}$

It is also seen that the interval of acceptable values of the asymmetry parameter $\gamma$ and the interval of rotation angles of PM, where the static and dynamic resistance are kept sharply narrow with decreasing the resonance frequency $f_{0}$, or with decreasing torsion stiffness.

\section{Conclusion}

It is impossible to achieve the ideal symmetry of the differential capacitive systems experimentally. There were no systematic studies of the effect of such asymmetry on the resulting stiffness of the suspensions of PM in gravi-inertial sensors taking into account their non-linearity.

In this paper it was found, in both quasi-static and dynamic modes of PM's free movement, that the asymmetry of the differential electrostatic system is the most important factor limiting the ability to reduce the stiffness of the suspension, or, the sensitivity of the sensor using an electric fields.

It is shown that the asymmetry of the differential capacitive system limits the area of the sustainability of PM's free oscillations much greater than the area of the quasi-static stability.
On the other side, the symmetry has to sharply increase with significant decrease of the its PM's natural frequency due to the electric field. Particularly, values of the natural frequency $f_{0}$, equal to $4 \mathrm{~Hz}$, or $2 \mathrm{~Hz}$, or $1 \mathrm{~Hz}$, can be obtained in the model of the sensor, which has the natural frequency in the absence of an electric field is $f \approx 14 \mathrm{~Hz}$, in case if the voltage source of the electric field are respectively $170,876 \mathrm{~V}$, or $176,185 \mathrm{~V}$, or $177,487 \mathrm{~V}$. In these cases, the free oscillation of PM will be stable with respect to the angular interval $\Delta_{d}^{+}=0.04$ (or in absolute values about 16 arc second), if the value of asymmetry $\gamma$ doesn't exceed $4 \%, 0,5 \%$, or $0,05 \%$. respectively. The last result imposes very strict requirements for sensor technology production.

Further investigation of the gravi-inertial differential capacitive sensor system's dynamics have to consider energy losses for friction and for the current flow in resistors of an electrical circuit during PM free and forced motion.

\section{References}

1. Milatz J.M.W., van Zolingen J.J. The Brownian Motion of Electrometers. Physica, 1953, vol. 19, issue 1, pp. 181-194.

2. Forward R.L. Measurement of static field gradient: US Patent no. 3273397, Filed 05.06.1964.

3. Bell C.C. Torsionally resonant gravity gradient sensor: US Patent no. 3564921, Filed 23.02.1971.

4. Dias R.A., Cretu E., Wolffenbuttel R., Rocha L.A. Pull-in-based $\mu$ g-resolution accelerometer: Characterization and noise analysis. Sensors and Actuators A: Physical, 2011, vol. 172(1), pp. 47-53.

5. Trusov A.A. Ultra high quality factor and wide dynamic range inertial MEMS for north-finding and tracking applications. Whitepaper Available at: http://www.alexandertrusov.com/uploads/pdf/2013-UCI-Trusov-whitepaper-FM-IMU.pdf (accessed 01.12.2015).

6. Forward R., Bell C., Morris J. Rotating gravitational sensors. Gravity Research Foundation Essay. Available at:http://www.gravityresearchfoundation.org/pdf/awarded/ 1965/ forward_bell_morris.pdf (accessed 19.12.2015).

7. Bernstein J. An Overview of MEMS Inertial Sensing Technology. Sensors online. Available at: http:// www.sensorsmag.com/sensors/acceleration-vibration/ an-overview-mems-inertial-sensing-technology-970 (accessed: 19.02.2015).

8. Zhang W.M., Yan H., Peng Z.K. Electrostatic pull-in instability in MEMS/NEMS: A review. Sensors and Actuators A: Physical, 2014, vol. 214, pp. 187-218.

9. Fuligni F., Lorenzini E., Bordoni E., Lazarewicz A.R., Iafolla V. Development of a High-Sensitivity, NonCryogenic Astrophysical Gravity Gradiometer for Space- 
borne Use Observatory. Proceedings of 14th Annual Gravity Gradiometry Conference, United States Air Force Academy, Colorado Springs, Colorado, 11-12 February 1986. USA, 1986, pp. 374-392.

10. Mekid S., Gilavdary I. Differential capacitance torque sensor: US Patent no. 8893563, Nov. 25, 2014.

11. McNeil A., Lin Y., Miller T. Differential capacitive sensor and method of making same: US Patent no. 7610809 , Nov. 3, 2009.
12. Gilavdary I., Mekid S., Riznookaya N. [Controlling of sensitivity of the sensor with differential electrostatic transducers]. Pribory $i$ metody izmerenij [Devices and methods of measurements], 2015, vol. 6, no. 2, pp. 163-172 (in Russian).

13. Korn G.A., Korn T.M. Mathematical handbook for scientists and engineers: definitions, theorems, and formulas for reference and review. New York, Dover Publications, 2000, $1130 \mathrm{p}$. 


\title{
Статическая и динамическая стабильность гравиинерциального датчика с емкостной дифференциальной системой управления чувствительностью
}

\author{
Джилавдари И. ${ }^{1}$, Мекид С. ${ }^{2}$, Ризноокая Н. ${ }^{1}$, Абдул Сатер А. ${ }^{1}$ \\ ${ }^{1}$ Белорусский национальный технический университет, \\ nр. Независимости, 65, 220013, г. Минск, Беларусь \\ ${ }^{2}$ Университет нефти и полезных ископаемых короля Фахда, \\ 31261, Дхахран, Саудовская Аравия \\ Поступила 05.01.2016 \\ Принята к печати 08.02.2016
}

Изучается конструкция гравиинерциального датчика с упруго подвешенной массой, обладающего максимальной чувствительностью и минимальным уровнем шума. Датчик содержит упругий торсион, электростатическую емкостную систему измерения движения подвижной массы и электростатическую емкостную систему уменьшения крутильной жесткости торсиона. Обе емкостные системы объединены в единую дифференциальную емкостную электростатическую систему. Аналитически и численно изучаются проблемы, возникающие в результате асимметрии этой системы. Исследуются квазистатический и динамический режимы свободного движения подвижной массы при отсутствии потерь энергии. Рассчитываются угловые интервалы устойчивости движения подвижной массы в электростатическом поле в зависимости от параметра асимметрии дифференциальной системы и от частоты свободных колебаний.

Ключевые слова: гравиинерциальные датчики, емкостной дифференциальный сенсор, эффект залипания, асимметрия дифференциального сенсора.

DOI: $10.21122 / 2220-9506-2016-7-1-16-23$

\begin{tabular}{ll}
\hline Адрес для переписки: & $\begin{array}{l}\text { Address for correspondence: } \\
\text { Джялавдари И. }\end{array}$ \\
$\begin{array}{l}\text { Белорусский национальный технический университет, } \\
\text { Belarusian National Technical University, } \\
\text { nр. Независимости, 65, 220013, г. Минск, Беларусь } \\
\text { e-mail:gilavdаry@bntu.by }\end{array}$ & $\begin{array}{l}\text { Nezavisimosty Ave., 65, 220013, Minsk, Belarus } \\
\text { e-mail:gilavdary@bntu.by }\end{array}$ \\
\hline Для цитирования: & For citation: \\
Gilavdary I., Mekid S., Riznookaya N., Abdul Sater A. & Gilavdary I., Mekid S., Riznookaya N., Abdul Sater A. \\
Static and dynamic stability of gravi-inertial sensors with capacitive & Static and dynamic stability of gravi-inertial sensors with capacitive \\
differential system of sensitivity adjustment. & differential system of sensitivity adjustment. \\
Приборы и методы измерений. & Pribory i metody izmerenj [Devices and Methods of Measurements], \\
2016. - Т. 7, № 1. - С. 16-23. & 2016, vol. 7, no. 1, pp. 16-23. \\
DОI: $10.21122 / 2220-9506-2016-7-1-16-23$ & DOI: 10.21122/2220-9506-2016-7-1-16-23
\end{tabular}

